\title{
Article \\ Mitochondrial Dynamics Markers and Related Signaling Molecules Are Important Regulators of Spermatozoa Number and Functionality
}

\author{
Isidora M. Starovlah (D, Sava M. Radovic Pletikosic, Tatjana S. Kostic (D) and Silvana A. Andric*D
}

\section{check for} updates

Citation: Starovlah, I.M.; Radovic Pletikosic, S.M.; Kostic, T.S.; Andric, S.A. Mitochondrial Dynamics Markers and Related Signaling Molecules Are Important Regulators of Spermatozoa Number and Functionality. Int. J. Mol. Sci. 2021, 22, 5693. https://doi.org/10.3390/ ijms22115693

Academic Editor: Pablo M García-Rovés

Received: 12 April 2021

Accepted: 13 May 2021

Published: 27 May 2021

Publisher's Note: MDPI stays neutral with regard to jurisdictional claims in published maps and institutional affiliations.

Copyright: (c) 2021 by the authors. Licensee MDPI, Basel, Switzerland. This article is an open access article distributed under the terms and conditions of the Creative Commons Attribution (CC BY) license (https:// creativecommons.org/licenses/by/ $4.0 /)$.
Laboratory for Reproductive Endocrinology and Signaling, Laboratory for Chronobiology and Aging, CeRES, DBE, Faculty of Sciences, University of Novi Sad, 21000 Novi Sad, Serbia; isidora.starovlah@dbe.uns.ac.rs (I.M.S.); sava.radovic@dbe.uns.ac.rs (S.M.R.P.); tatjana.kostic@dbe.uns.ac.rs (T.S.K.)

* Correspondence: silvana.andric@dbe.uns.ac.rs; Tel.: +381-63-748-4403

Abstract: Here, we study possible mechanisms of (in/sub)fertility related to the acute or repeated psychological stresses (the most common stresses in human society) by following the transcriptional profile of 22 mitochondrial dynamics/function markers and 22 signaling molecules regulating both mitochondrial dynamics and spermatozoa number/functionality. An in vivo study mimicking acute (once for $3 \mathrm{~h}$ ) and repeated ( $3 \mathrm{~h}$ for 10 consecutive days) psychophysical stress was performed on adult rats. The analysis of hormones, the number/functionality of spermatozoa, and 44 transcriptional markers were performed on individual samples from up to 12 animals per group. Results showed that both types of stress reduced spermatozoa functionality (acute by 4.4-fold, repeated by 3.3-fold) and ATP production (acute by 2.3-fold, repeated by 14.5-fold), while only repeated stress reduces the number of spermatozoa (1.9-fold). Stress significantly disturbed transcription of 34-out-of-44 markers (77\%). Mitochondrial dynamics and functionality markers: 18-out-of-22 $=>82 \%$ (mitochondrial-biogenesis-markers $->6$-out-of- $8=>75 \%$; mitochondrial-fusion-markers $->3$ out-of-3 =>100\%; mitochondrial-fission-markers $\rightarrow$ - -out-of- $2=>50 \%$; mitochondrial-autophagymarkers $\rightarrow>3$-out-of-3 =>100\%; mitochondrial-functionality-markers $\rightarrow>5$-out-of- $6=>83 \%$ ). Markers of signaling pathways regulating both mitochondrial dynamics/functionality and spermatozoa number/functionality important for male (in/sub)fertility $\rightarrow>16$-out-of- $22=>73 \%$ (cAMP-signalingmarkers $->8$-out-of- $12=>67 \%$; MAPK-signaling-markers $\rightarrow>8$-out-of- $10=>80 \%$ ). Accordingly, stresstriggered changes of transcriptional profile of mitochondrial dynamics/functionality markers as well as signaling molecules regulating both mitochondrial dynamics and spermatozoa number and functionality represent adaptive mechanisms.

Keywords: acute/repeated psychological stress; mitochondrial dynamics and functionality markers; cAMP signaling markers; MAPK signaling markers; spermatozoa number and functionality

\section{Introduction}

The miracle of life starts with fertilization and requires perfect spermatozoa functionality, which is a highly energy driven and demanding process regulated by complex as well as a wide network of signaling pathways. According to the World Health Organization (WHO), the overall burden of (sub/in)fertility is high, unknown in men, underestimated, and has not displayed any decrease over the last 20 years. Accordingly, the investigations of the mechanisms of (sub/in)fertility are urgent (https:/ / www.who. int/r1eproductivehealth/topics/infertility/perspective/en/, accessed on 5 April 2021). Besides the aforementioned, many studies showed the increase of unexplained cases of infertile young males and decrease of the fertility rate in men younger than age 30 . This is important, since the semen quality and male fertility are important as the fundamental marker of reproductive health and the fundamental biomarker of overall health $[1,2]$. The correlation between male (sub/in)fertility and stressful life has been reported $[1,3,4]$. The 
stress enhanced rat testicular germ cell apoptosis [5] and induced irreversible loss of germ cells and spermatozoa number [6]. Although stress is an adaptive response of an organism enabling survival and maintaining homeostasis [7], if repeated or persistent/chronic, it can cause diseases [8-12]. Different types of stressors, as well as major stressful life events, have been linked to reduced male reproductive function $[3,13,14]$. A higher number of stressful life events are observed in infertile men, and this was associated with a decline in semen quality during fertility treatment [3]. Epidemiological studies showed that DNA damage during stress-response is regulated through $\beta 2$-adrenergic-receptors [15], strongly suggesting the importance of stress-signaling in regulation of mitochondrial homeostasis.

Mitochondria are key linking point between stress-response and spermatozoa functionality since they are responsible for satisfying enormous energy demands required for both processes $[1,8,9,12]$. Furthermore, both stress signaling and mitochondria are essential for spermatozoa functionality. The spermatogenesis and fertility are disturbed in $\alpha 1$-adrenergic-receptors-knockout-male-mice [16]. The functionality of mitochondria differentiates human spermatozoa with high and low fertilizing capability [17]. It has been shown that mtDNA depletion may play an important role in the pathophysiology of male infertility [18] serving as a diagnostic marker of sperm quality in infertile men [19]. Additionally, the stages of spermatogenesis are characterized with the changes in mitochondrial morphology [20], and these changes shed light on the unexplained asthenozoospermia with altered ultrastructure of mitochondria [21]. Defects of mtDNA in oligoasthenozoospermic patients made DNA unavailable for amplification [22]. Large-scale deletions of mtDNA were pointed to as risk factors for poor sperm quality in asthenoteratozoospermia-induced male infertility [23]. Beside mtDNA, the importance of mitochondrial membrane potential is recognized not only for spermatozoa functionality [24-26], but also, in combination with sperm DNA fragmentation, as standard semen parameter for the prediction of natural conception [27]. Moreover, mitochondrial transcription factor TFAM (Transcription Factor A, Mitochondrial) causes the reduction of mtDNA content in human sperm [28], and the expression of TFAM gene positively correlates with abnormal forms, sperm DNA fragmentation, and mtDNA copy number $[29,30]$. Human sperm motility and viability are regulated by mitophagy [31]. The loss of human spermatozoa motility is mitigated by UCP2 (uncoupling protein 2) [32], while the motility and cryoprotective potential of human sperm is connected with the MFN2 (mitofusin 2) expression level [33]. According to everything mentioned above, the mitochondria are a crucial organelle for spermatozoa functionality, and their homeostasis strongly correlates with (sub/in)fertility [1]. Although profiles of signaling proteins in human spermatozoa suggested that the phosphorylated levels of several proteins were significantly associated with motility parameters [34] and these proteins regulate mitochondrial-network-homeostasis, to the best of our knowledge, there are no published pieces of evidence about the transcriptional profile of mitochondrial dynamic markers and related signaling molecules in spermatozoa from a stressed organism.

The mitochondrial network homeostasis is kept and maintained by well-coordinated, but intriguing, processes of mitochondrial dynamics including the complex mitochondrial protein-import machinery (mitochondrial transduceom), movement of mitochondria to position themselves strategically in the cell (motility/trafficking), mitochondrial biogenesis, mitofusion, mitofission, and mitophagy [35-38]. All of these are interplay of a sophisticated and multistep molecular events required for renewal, adaptation, or expansion of mitochondrial network in a cell during episodes of damage or periods of intensified energy demand [28,39-41]. Nucleo-mitochondrial interactions are required for the spatiotemporal regulation of mitochondrial dynamics and are dependent on the interplay between transcription factors and members of the PGC1 (peroxisome proliferator-activated receptor gamma coactivator 1 ) family of coactivators (PGC1 $\alpha, P G C 1 \beta, P R C)$ regulating the expression of main markers of mitochondrial dynamic $[35,36]$. These main markers of mitochondrial dynamics include markers of mitochondrial biogenesis (PGC1 $\alpha$, PGC1 $\beta$, NRF1, NRF2 (nuclear respiratory factor 1 and 2), TFAM), mitofusion (MFN1, MFN2, OPA1 (mitochondrial dynamin like GTPase)), mitofission (DRP1 (dynamin-related protein 1), FIS1 
(mitochondrial fission protein 1)), and mitophagy (PINK (PTEN induced kinase), PARKIN), as well as important markers of the respiratory chain function [35-38,40,41]. Mitochondrial dynamic processes are controlled by an intriguing and complex network of cellular signaling pathways $[36,39,41]$ conveying different environmental signals: stress [42,43], temperature [44], energy deprivation [41], availability of nutrients [41], and growth factors [45]. More importantly, all signaling pathways regulating mitochondrial dynamics are essentially involved in the regulation of spermatozoa function. The recent review article pointed out the great gap and interest in the research related to mitochondria and male fertility [46]. Many studies discussed the correlation between stress and/or stressful life and male (in)fertility [3]. Yet, the mechanisms are not described.

Since our previous ex vivo studies showed importance of adrenergic signaling in regulation of mitochondrial dynamics markers, here we hypothesize that the psychophysical stress alters the changes of mitochondrial dynamics and functionality markers as well as signaling molecules regulating both mitochondrial dynamics and spermatozoa number and functionality.

\section{Results}

In the search for any possible mechanism(s) of the (in/sub)fertility related to spermatozoa functionality, the in vivo approach was designed to mimic situations in human population exposed to acute and repeated psychological stress, the most common stress in human society. This was achieved by applying the immobilization (IMO) stress of $3 \mathrm{~h}$ for once $(1 \times 3 \mathrm{hIMO}$, acute) or for 10 consecutive days $(10 \times 3 \mathrm{hIMO}$, repeated $)$ on the adult male rat $[13,14,47]$.

\subsection{Repeated Psychophysical Stress Increases the Level of Stress Hormones in Circulation, but} Decreases Androgens Levels, as Well as the Functionality, ATP Level and Number of Spermatozoa

The effects of the acute $(1 \times 3 \mathrm{hIMO})$ as well as repeated $(10 \times 3 \mathrm{hIMO})$ stress were in agreement with previous studies $[13,14,47]$ since IMO was effective as a stressor (Figure 1) elevating the serum adrenaline of acutely $(1 \times 3 \mathrm{hIMO} \rightarrow 3.1$-fold $)$ and repeatedly $(10 \times 3 \mathrm{hIMO}$ $\rightarrow 2.9$-fold) stressed animals. Similar effects were observed on the level of corticosterone $(1 \times 3 \mathrm{hIMO} \rightarrow 66.6$-fold; $10 \times 3 \mathrm{hIMO}->6.4$-fold $=>544.1 \%)$. Conversely, circulating androgens $(\mathrm{T}+\mathrm{DHT})$ were reduced in both stressed groups $(1 \times 3 \mathrm{hIMO} \rightarrow 5$.7-fold, $10 \times 3 \mathrm{hIMO}$ $\rightarrow 10.5$-fold). Repeated stress $(10 \times 3 \mathrm{hIMO})$ significantly reduced (1.9-fold) the number of spermatozoa, while both types of stress significantly inhibited spermatozoa functionality $(1 \times 3 \mathrm{hIMO} \rightarrow 4.4$-fold; $10 \times 3 \mathrm{hIMO} \rightarrow 3.3$-fold $)$ as well as ATP production $(1 \times 3 \mathrm{hIMO}$ $\rightarrow 2.3$-fold, $10 \times 3 \mathrm{hIMO} \rightarrow$ 14.5-fold).

Unlike ever before, the transcriptional profile of mitochondrial dynamics markers and signaling molecules regulating both mitochondrial dynamics and spermatozoa number and functionality (important for fertilization) were explored to reveal any possible mechanism(s) beyond these effects. Results showed that stress dramatically disturbed the expression of transcripts for the markers of mitochondrial dynamics and functionality as well as related signaling pathways, since the expression levels of 34-out-of- $44(70 \%)$ were changed (Figures 2-4). 


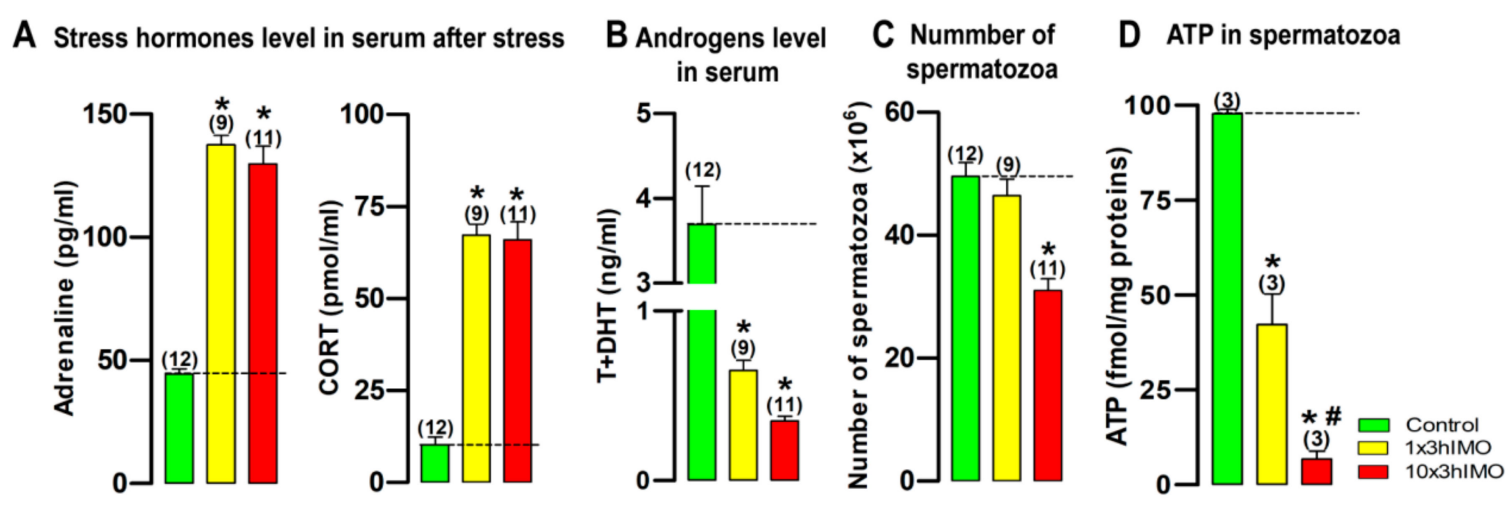

E Functionality of spermatozoa after stress
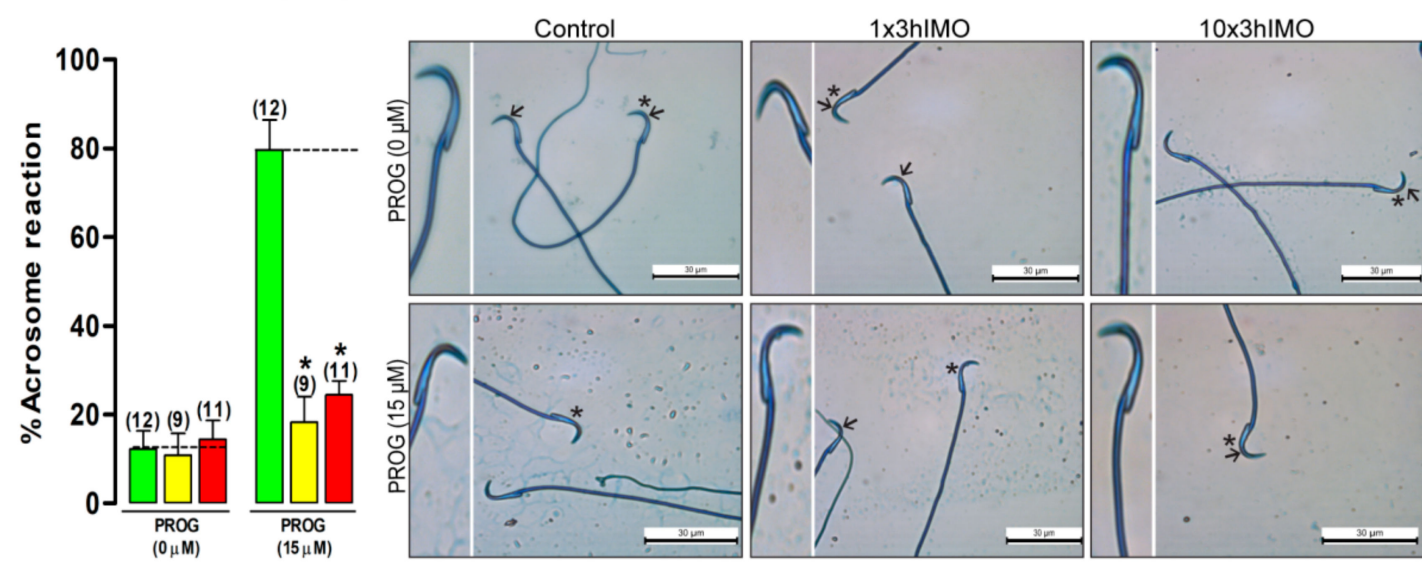

Figure 1. The repeated psychophysical stress increases the level of stress hormones in circulation, but decreases androgens levels, as well as the functionality, ATP level, and number of spermatozoa. The circulating (serum) levels of (A) stress hormones adrenaline and corticosterone (CORT), as well as (B) androgens (testosterone + dihydrotestosterone, $\mathrm{T}+\mathrm{DHT}$ ) after psychophysical stress by immobilization. (C) The number of spermatozoa isolated from caudal epididymides of unstressed rats (control), rats subjected to acute immobilization (IMO) stress once, for $3 \mathrm{~h}(1 \times 3 \mathrm{hIMO})$, and rats subjected to repeat IMO of $3 \mathrm{~h}$ for 10 consecutive days $(10 \times 3 \mathrm{hIMO})$. (D) ATP content in spermatozoa isolated from control, acutely $(1 \times 3$ hIMO $)$ or repeatedly $(10 \times 3$ hIMO) stressed rats. $($ E) The functionality of spermatozoa $(\%$ of acrosome reacted spermatozoa) isolated from control and acutely $(1 \times 3 \mathrm{hIMO})$ and repeatedly $(10 \times 3 \mathrm{hIMO})$ stressed rats. Capacitated spermatozoa were stimulated with progesterone (PROG $15 \mu \mathrm{M})$ in parallel with spermatozoa not treated with progesterone (PROG $0 \mu \mathrm{M})$. Blue staining in the acrosome region of the head indicated intact acrosome, whereas spermatozoa without blue staining in the acrosome region were considered to be acrosome reacted. Arrows indicate acrosome intact spermatozoa; scale bar $30 \mu \mathrm{m}$. Star indicates spermatozoa magnified on the right panel. Data bars are mean \pm SEM values of three independent in vivo experiments. Statistical significance was set at level $p<0.05:{ }^{*}$ vs. control group; \# vs. $1 \times 3$ hIMO group.

\subsection{Transcriptional Profiles of Mitochondrial Dynamics and Functionality Markers Are Dramatically Changed in Spermatozoa from Stressed Rats}

Markers of mitochondrial dynamics and functionality in spermatozoa are under significant influence of stress hormones since transcriptional levels of 18-out-of-22 (82\%) were changed (Figure 2).

Levels of 6-out-of-8 (75\%) transcripts for mitochondrial biogenesis markers increased in spermatozoa in stressed rats. Acute stress $(1 \times 3 \mathrm{hIMO})$ significantly increased spermatozoal Ppard (1.9-fold), while effects of repeated stress $(10 \times 3 \mathrm{hIMO})$ were more prominent since transcription of 6-out-of- $8=>75 \%$ markers were increased. The level of Ppargc1a, encoding PGC1, the master regulator involved in transcriptional control of all processes related to mitochondrial homeostasis and integrator of environmental signals [35,36], significantly increased (2.7-fold). This was followed by increased transcription of its down- 
stream-targets that act on genes for subunits of the oxidative phosphorylation (OXPHOS): Nrf1 (2.3-fold), Nrf2a (1.8-fold), Tfam (1.9-fold), $m t N d 1$ (7-fold), and Ppard (1.8-fold).

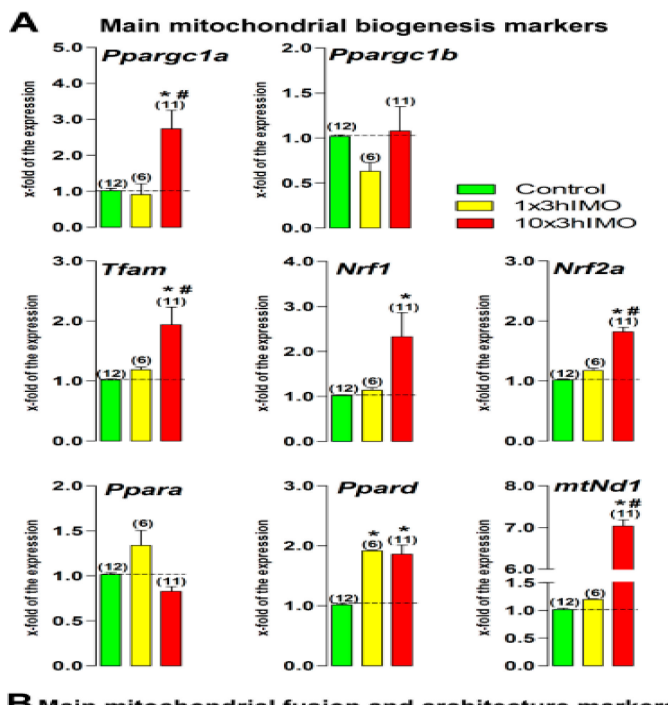

$B$ Main mitochondrial fusion and architecture markers

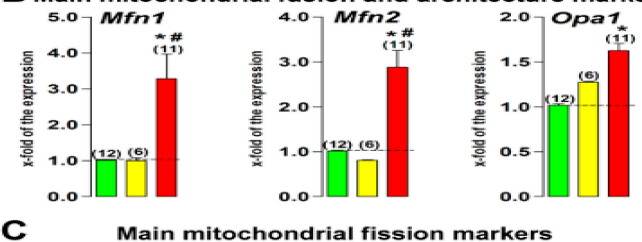

C

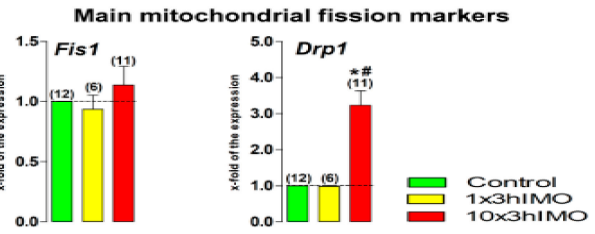

D Main mitochondrial autophagy markers

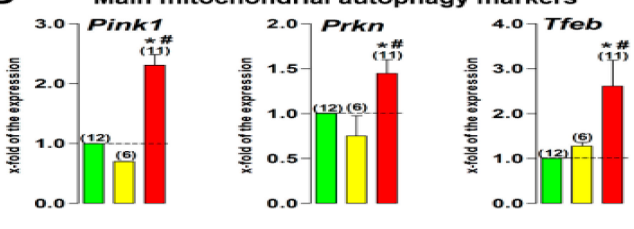

E Main mitochondrial functionality markers

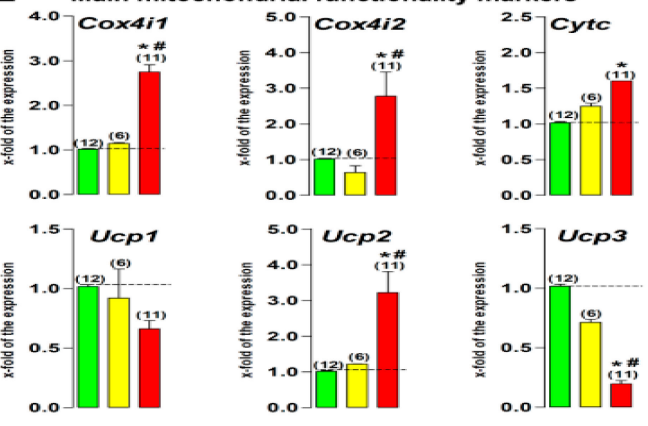

Figure 2. The transcriptional profiles of mitochondrial dynamics and functionality markers are significantly changed in spermatozoa of repeatedly stressed adult rats. RNA isolated from spermatozoa obtained from undisturbed and stressed rats were used for analysis of the transcriptional profile of markers of mitochondrial biogenesis (A), mitochondrial fusion and architecture (B), mitochondrial fission (C), mitochondrial autophagy (D), and mitochondrial functionality (E). Data bars are mean \pm SEM values of three independent in vivo experiments. Statistical significance was set at level $p<0.05$ : $^{*}$ vs. control group; \# vs. $1 \times 3 \mathrm{hIMO}$ group. 
A CAMP signaling markers
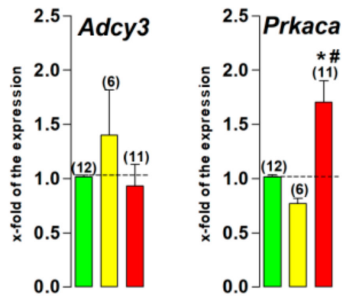

$\left.{ }^{1.5}\right\rceil$ Adcy5
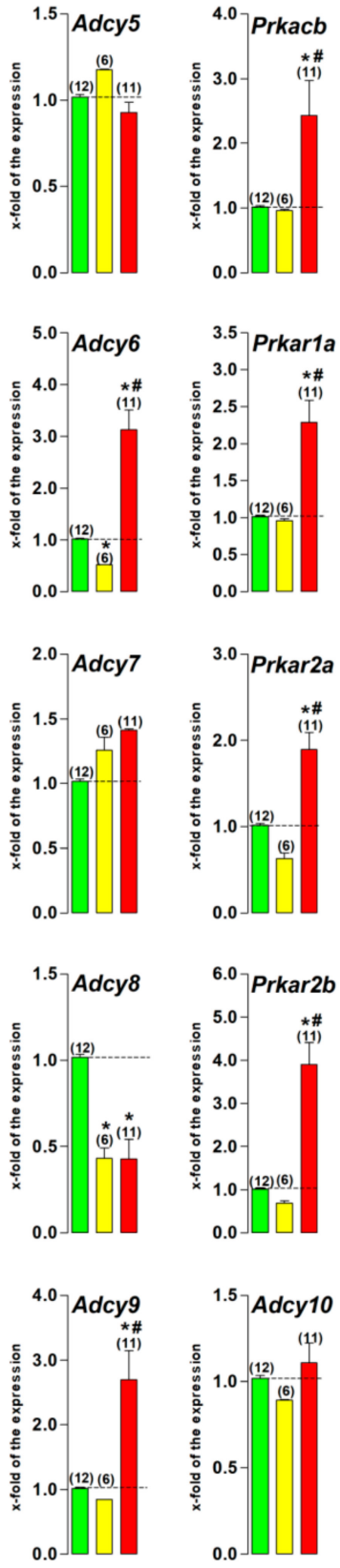

B MAPK signaling markers
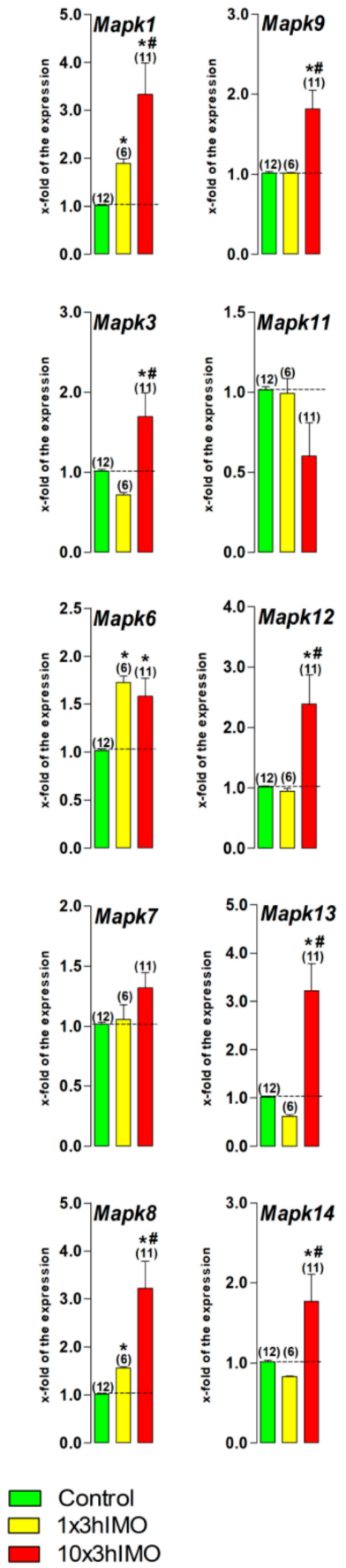

Figure 3. The transcriptional profiles of signaling molecules regulating mitochondrial dynamics and functionality as well as spermatozoa number and functionality are changed in spermatozoa of repeatedly stressed adult rats. RNA isolated from spermatozoa obtained from undisturbed and stressed rats were used for analysis of the transcriptional profile of markers of cAMP signaling (A) and MAPK signaling (B) pathways. Data bars are mean \pm SEM values of three independent in vivo experiments. Statistical significance was set at level $p<0.05$ : * vs. control group; \# vs. $1 \times 3$ hIMO group. 


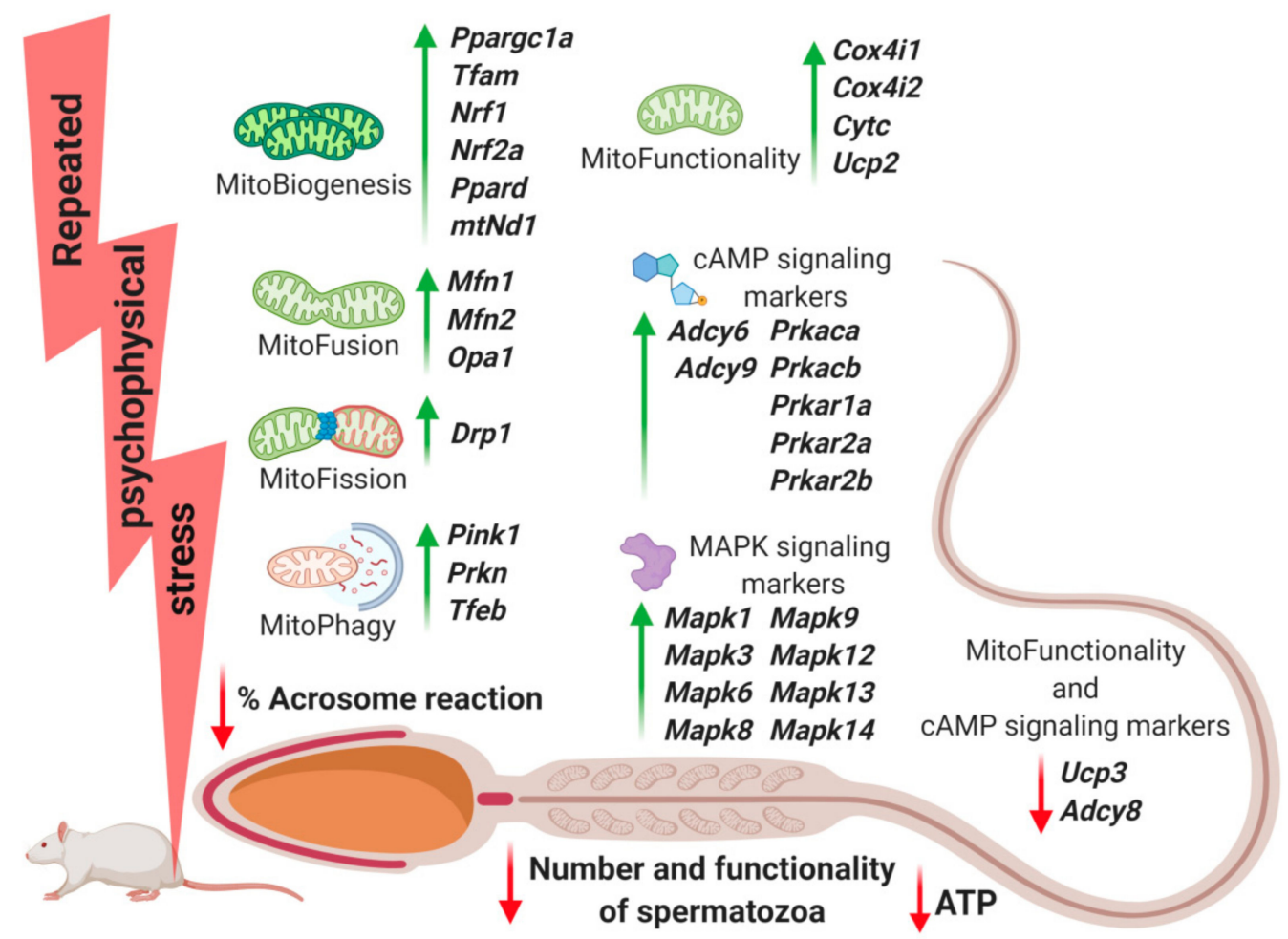

Figure 4. Repeated psychophysical stress disturbs the transcriptional profiles of mitochondrial dynamics and functionality markers and related signaling molecules, leading to the decrease in spermatozoa number and functionality. Repeated stress reduces the number of spermatozoa (1.9-fold $=>48 \%$ ), spermatozoa functionality (3.3-fold $=>69 \%)$, and ATP levels $(14.5$-fold $=>93 \%)$, as well as significantly disturbed transcription of $77 \%$ (34-out-of-44) markers. Mitochondrial dynamics and functionality $\rightarrow$ 18-out-of- $22=>82 \%$ (mitochondrial-biogenesis-markers $\rightarrow>6$-out-of- $8=>75 \%$; mitochondrial-fusionmarkers $->3$-out-of-3 =>100\%; mitochondrial-fission-markers $->1$-out-of- $2=>50 \%$; mitochondrialautophagy-markers $->3$-out-of-3 $=>100 \%$; mitochondrial-functionality-markers $->5$-out-of- $6=>83 \%$ ). Markers of signaling pathways regulating both mitochondrial dynamics/functionality and spermatozoa number/functionality important for male (in/sub)fertility $\rightarrow$ 16-out-of-22 $=>73 \%$ (cAMPsignaling-markers $\rightarrow>8$-out-of-12 $=>67 \%$; MAPK-signaling-markers $->8$-out-of- $10=>80 \%$ ).

Levels of transcripts for all (3-out-of-3 =>100\%) mitochondrial fusion markers increased in spermatozoa in repeatedly stressed rats. Repeated stress significantly increased all spermatozoal mitofusion and mito-architecture markers: Mfn1 (3.3-fold), Mfn2 (2.9-fold) and Opa1 (1.6-fold).

Level of transcript for 1-out-of-2 (50\%) mitochondrial fission marker increased in spermatozoa in repeatedly stressed rats. In the same samples used to obtain the aforementioned results, repeated stress increased Drp1 (3.2-fold), while Fis1 remained unchanged.

Levels of transcripts for all (3-out-of-3 $=>100 \%$ ) mitochondrial autophagy markers increased in spermatozoa in repeatedly stressed rats. Repeated stress increased transcription of Pink1 (2.3-fold), Prkn (1.45-fold), and Tfeb (2.6-fold).

Levels of transcripts for 5-out-of-6 (83\%) mitochondrial functionality markers were changed. In the same samples used to obtain the aforementioned results, significant changes in the transcriptional profiles of mitochondrial functional markers as well as NRF1/NRF2 downstream targets (CytC, COX4 and UCPs) were observed in spermatozoa in repeatedly stressed rats. Increased expressions of transcripts for Cox4i1 (2.7-fold), Cox4i2 (2.8-fold) and CytC (1.6-fold) were detected. Furthermore, repeated stress significantly changed the transcriptional profile of genes encoding proteins regulating the proton leak and the production of reactive oxygen species [44]. The increased level of transcript for Ucp2 (3.2-fold), the most prominently expressed UCP gene in spermatozoa ( $U c p 2-\mathrm{Ct}=22.65$ $\left.>U_{c p} 3-\mathrm{Ct}=29.24>U_{c p 1}-\mathrm{Ct}=29.73\right)$, was observed in repeatedly stressed rats spermatozoa. 
Conversely, in the same samples, the level of transcript for Ucp3 decreased (5.1-fold), while Ucp1 remained unchanged.

Given the central importance of cAMP and MAPK signaling, not only for regulation of mitochondrial dynamics and functionality $[35,36,40]$, but also for regulation of spermatozoa number and functionality [34], transcriptional profiles of main signaling molecules were explored.

2.3. Transcriptional Profiles of Signaling Molecules Regulating Mitochondrial Dynamics and Functionality as Well as Number and Functionality of Spermatozoa, All of Which Are Important for Fertility, Are Dramatically Changed in Spermatozoa from Stressed Rats

The markers of signaling pathways regulating both mitochondrial dynamics and functionality as well as spermatozoa number/functionality important for male (in)fertility are under significant influence of stress hormones, since transcriptional levels of 16-out-of$22(73 \%)$ were changed (Figure 3$)$.

Levels of transcripts for 8-out-of-12 (67\%) cAMP signaling-markers were changed in spermatozoa in stressed rats. Acute stress $(1 \times 3 \mathrm{hIMO})$ significantly decreased spermatozoal transcripts for Adcy6 (1.9-fold), and Adcy8 (2.3-fold). Repeated stress $(10 \times 3 \mathrm{hIMO})$ exhibited the opposite effect on Adcy6 (3.1-fold increase), yet a similar effect on Adcy8 (2.3-fold decrease). In the same spermatozoa, the level of transcript for Adcy9 increased (2.7-fold). In parallel, repeated stress significantly increased the expression of transcripts for genes encoding catalytic and regulatory PRKA subunits: Prkaca (1.7-fold), Prkacb (2.4-fold), Prkar1a (2.3-fold), Prkar2a (1.9-fold), and Prkar2b (3.9-fold).

Levels of transcripts for 8-out-of-10 (80\%) MAPK signaling markers increased in spermatozoa in stressed rats. Acute stress significantly increased spermatozoal transcripts for Mapk1 (1.9-fold), Mapk6 (1.7-fold), and Mapk8 (1.6-fold). Repeated stress significantly increased levels of transcripts for Mapk1 (3.3-fold), Mapk3 (1.7-fold), Mapk6 (1.6 -fold), Mapk8 (3.2-fold), Mapk9 (1.8-fold), Mapk12 (2.4-fold), Mapk13 (3.2-fold), and Mapk14 (1.8-fold).

\section{Discussion}

For the first time our results show that stress triggers changes of transcriptional profile of mitochondrial dynamics and functionality markers as well as signaling molecules (Figure 4) regulating both mitochondrial dynamics and spermatozoa number and functionality. Since most of the effects $(91 \%)$ on the level of the transcripts are a significant increase (please see Table 1) they could represent adaptive mechanisms to keep spermatozoa functionality. With changing the transcriptional profiles, spermatozoa may be trying to preserve the basic mitochondrial network homeostasis and self-activity since both types of stress significantly decreased ATP production. It is important to point out that affected molecules are essential for spermatozoa functionality and accordingly also for (in/sub)fertility. Several lines of evidence prove the above mentioned. (1) Repeated psychophysical stress reduces the number of spermatozoa. (2) Both types of stress, acute and repeated, significantly reduced spermatozoa functionality and ATP level in spermatozoa. (3) Stress significantly disturbed transcription of $77 \%$ markers of mitochondrial dynamics/functionality as well as signaling pathways regulating both mitochondrial homeostasis and fertility. All aforementioned signaling molecules are very well known as essential regulators of spermatozoa number and functionality [34], as well as regulators of mitochondrial dynamics markers $[35,36,40]$, and therefore are very important for (in/sub)fertility. 
Table 1. The transcriptional profiles of mitochondrial dynamics and functionality markers and signaling molecules regulating mitochondrial dynamics and functionality as well as spermatozoa number and functionality are significantly changed in spermatozoa of repeatedly stressed adult rats. Data are presented as means \pm SEM values of three independent experiments. Statistical significance at level $p<0.05$ : * vs. control group; \# vs. $1 \times 3$ hIMO group.

\begin{tabular}{|c|c|c|c|}
\hline Transcript $\quad$ Group & Control & $1 \times 3 \mathrm{hIMO}$ & $10 \times 3$ hIMO \\
\hline Ppargc1a & $1.0 \pm 0.07$ & $\mathbf{0 . 9 1} \pm 0.30$ & $2.74^{*, \#} \pm 0.52 \uparrow$ \\
\hline Tfam & $\mathbf{1 . 0} \pm 0.02$ & $1.19 \pm 0.04$ & $1.94^{*, \#} \pm 0.29 \uparrow$ \\
\hline$N r f 1$ & $1.0 \pm 0.02$ & $\mathbf{1 . 1 4} \pm 0.06$ & $2.33^{*} \pm 0.54 \uparrow$ \\
\hline$N r f 2 a$ & $1.0 \pm 0.06$ & $\mathbf{1 . 1 8} \pm 0.04$ & $1.82^{*, \#} \pm 0.08 \uparrow$ \\
\hline Ppard & $\mathbf{1 . 0} \pm 0.01$ & $1.92 * \pm 0.01 \uparrow$ & $\mathbf{1 . 8 6} * \pm 0.15 \uparrow$ \\
\hline$m t N d 1$ & $1.0 \pm 0.02$ & $\mathbf{1 . 2 0} \pm 0.01$ & $7.03^{*, \#} \pm 0.16 \uparrow$ \\
\hline$M f n 1$ & $\mathbf{1 . 0} \pm 0.01$ & $1.00 \pm 0.08$ & $3.28^{*, \#} \pm 0.69 \uparrow$ \\
\hline$M f n 2$ & $\mathbf{1 . 0} \pm 0.04$ & $\mathbf{0 . 8 1} \pm 0.01$ & $2.88^{*, \#} \pm 0.37 \uparrow$ \\
\hline Opa1 & $\mathbf{1 . 0} \pm 0.06$ & $1.27 \pm 0.01$ & $1.63 * \pm 0.08 \uparrow$ \\
\hline Drp1 & $\mathbf{1 . 0} \pm 0.01$ & $\mathbf{0 . 9 8} \pm 0.03$ & $3.23^{*, \#} \pm 0.39 \uparrow$ \\
\hline Pink1 & $1.0 \pm 0.00$ & $\mathbf{0 . 7 0} \pm 0.01$ & $2.31^{*, \#} \pm 0.18 \uparrow$ \\
\hline Prkn & $\mathbf{1 . 0} \pm 0.05$ & $\mathbf{0 . 7 5} \pm 0.23$ & $1.45^{*, \#} \pm 0.15^{\uparrow}$ \\
\hline$T f e b$ & $\mathbf{1 . 0} \pm 0.01$ & $1.28 \pm 0.08$ & $\mathbf{2 . 6 1}{ }^{*, \#} \pm 0.59 \uparrow$ \\
\hline Cox4i1 & $1.0 \pm 0.02$ & $1.15 \pm 0.02$ & $2.75^{*, \#} \pm 0.17 \uparrow$ \\
\hline Cox4i2 & $1.0 \pm 0.02$ & $\mathbf{0 . 6 4} \pm 0.19$ & $2.78^{*, \#} \pm 0.68 \uparrow$ \\
\hline Cytc & $\mathbf{1 . 0} \pm 0.01$ & $1.25 \pm 0.04$ & $1.60 * \pm 0.08 \uparrow$ \\
\hline Ucp2 2 & $1.0 \pm 0.02$ & $1.23 \pm 0.01$ & $3.22^{*, \#} \pm 0.59 \uparrow$ \\
\hline Ucp3 & $1.0 \pm 0.06$ & $\mathbf{0 . 7 1} \pm 0.03$ & $\mathbf{0 . 2 0}{ }^{*, \#} \pm 0.02 \downarrow$ \\
\hline Adcy 6 & $\mathbf{1 . 0} \pm 0.02$ & $\mathbf{0 . 5 2} * \pm 0.01 \downarrow$ & $3.13^{*, \#} \pm 0.38 \uparrow$ \\
\hline Adcy 8 & $\mathbf{1 . 0} \pm 0.01$ & $\mathbf{0 . 4 3} 3^{*} \pm 0.06 \downarrow$ & $\mathbf{0 . 4 3} * \pm 0.11 \downarrow$ \\
\hline Adcy9 & $\mathbf{1 . 0} \pm 0.01$ & $\mathbf{0 . 8 5} \pm 0.00$ & $2.70^{*, \#} \pm 0.45 \uparrow$ \\
\hline Prkaca & $1.0 \pm 0.02$ & $\mathbf{0 . 7 7} \pm 0.05$ & $1.70^{*, \#} \pm 0.19 \uparrow$ \\
\hline Prkacb & $1.0 \pm 0.02$ & $\mathbf{0 . 9 6} \pm 0.02$ & $2.43^{*, \#} \pm 0.54 \uparrow$ \\
\hline Prkar1a & $\mathbf{1 . 0} \pm 0.01$ & $\mathbf{0 . 9 6} \pm 0.02$ & $2.29^{*, \#} \pm 0.30 \uparrow$ \\
\hline Prkar2a & $1.0 \pm 0.02$ & $\mathbf{0 . 6 3} \pm 0.06$ & $1.89^{*, \#} \pm 0.20 \uparrow$ \\
\hline Prkar2b & $1.0 \pm 0.02$ & $\mathbf{0 . 6 8} \pm 0.05$ & $3.90^{*, \#} \pm 0.51 \uparrow$ \\
\hline Mapk1 & $\mathbf{1 . 0} \pm 0.01$ & $1.89 * \pm 0.09 \uparrow$ & $3.33^{*, \#} \pm 0.65 \uparrow$ \\
\hline Mapk3 & $1.0 \pm 0.02$ & $\mathbf{0 . 7 2} \pm 0.04$ & $1.70^{*, \#} \pm 0.29 \uparrow$ \\
\hline Mapk6 & $\mathbf{1 . 0} \pm 0.02$ & $1.72 * \pm 0.06 \uparrow$ & $\mathbf{1 . 5 8}{ }^{*} \pm 0.19 \uparrow$ \\
\hline Mapk8 & $\mathbf{1 . 0} \pm 0.01$ & $1.56 * \pm 0.03 \uparrow$ & $3.22 *, \# \pm 0.56 \uparrow$ \\
\hline Mapk9 & $1.0 \pm 0.02$ & $\mathbf{1 . 0 2} \pm 0.01$ & $1.82^{*, \#} \pm 0.23 \uparrow$ \\
\hline Mapk12 & $\mathbf{1 . 0} \pm 0.01$ & $0.95 \pm 0.05$ & $2.39^{*, \#} \pm 0.48 \uparrow$ \\
\hline Mapk13 & $1.0 \pm 0.02$ & $\mathbf{0 . 6 1} \pm 0.04$ & $3.25^{*, \#} \pm 0.56 \uparrow$ \\
\hline Mapk14 & $\mathbf{1 . 0} \pm 0.01$ & $\mathbf{0 . 8 3} \pm 0.01$ & $1.77^{*, \#} \pm 0.34 \uparrow$ \\
\hline
\end{tabular}

Results presented in this and our recently published article [14] are in line with others showing that chronic intermittent stress decreases sperm number [6], the number of spermatogenic cells [48], sperm motility [49], and sperm quality [50] in male rats. The inhibitory role of stress hormones on sperm functionality is in line with stress-inducedGRs-signaling-mediated spermatogenesis impairment [51] as well as reduced testosterone and sperm motility in high and moderate male runners [52]. Furthermore, fertility and spermatogenesis are altered in $\alpha 1$-ADRs-knockout-male-mice [16]. In humans, stress 
was associated with a reduction in percentage of progressively motile sperm [53] and patients with post-traumatic stress disorder have higher secondary infertility [54]. All of the aforementioned suggests the important and complex involvement of stress signaling in spermatogenesis and fertility.

It is clear that the repeated stress dramatically changed transcriptional pattern of mitochondrial dynamics/functionality markers as well as signaling molecules regulating both mitochondrial homeostasis and fertility by increasing the transcription of 30-out-of-32 (94\%) genes (Table 1 and Figure 4). This increase could be the possible adaptive mechanism to keep energy balance and preserve capabilities for fertilization. It is difficult to compare our finding since there is not a lot of evidence available from other authors. However, it has been shown that PPARGC1A and PRKAR1A are changed in spermatozoa of type 2 diabetes mellitus patients [55]. Furthermore, an increase in Nrf2 diminished testicular inflammation [56], while TFAM gene expression positively correlates with abnormal forms, sperm DNA fragmentation, and mtDNA copy number [29,30]. TFAM is essential for mammalian mtDNA transcription in animals and humans. It has been reported that a testis-specific mouse TFAM isoform lacks the mitochondrial targeting sequence and is present only in the nucleus of spermatocytes and elongating spermatids [57]. Our observations about significant increase in the level of Uсp2 in spermatozoa from both stressed and adrenaline-stimulated spermatozoa [14] could be a possible explanation for findings of other authors showing that the presence of UCP2 mitigates the loss of human spermatozoa motility [32]. Since the transcripts for main markers (Mfn1, Mfn2, Opa1) of mitochondrial fusion/architectures, important for homeostasis of mitochondrial network and functionality $[35,36,40]$, were dramatically increased in spermatozoa from stressed rats, these results may explain results of other authors showing the positive relation of the expression level of MFN2 with motility and cryoprotective potential of human sperm [33], as well as mitofusin-mediated promotion of OXPHOS [58]. It has been shown that Cox4i1 (gene encoding the terminal enzyme in the mitochondrial respiratory chain and transcript increased in spermatozoa from stressed rats) is also significantly increased in sperm of obese males mice [59] and could be important for male infertility treatment [60]. Additionally, our results showing that repeated stress increased Cytc is related with the findings that perturbed mitochondrial release of $\mathrm{CytC}$ in human spermatozoa may be the distinguishing molecular feature between oligospermia and asthenospermia [61].

The final important insight from our study is that the psychophysical stress significantly disturbed transcription of signaling pathways (cAMP and MAPK signaling) regulating both mitochondrial dynamics and spermatozoa number/functionality. All aforementioned signaling molecules are very well known as essential regulators of spermatozoa number and functionality [34], as well as regulators of PGC1, the biogenesis of OXPHOS, mitofusion, mitofission, and mitophagy $[35,36,40]$ and that they are very important for fertility. It is very difficult to provide precise mechanism since it is very well known that signaling network in spermatozoa is complex and very precisely regulated to provide fertility homeostasis in health and diseases [62]. Besides, there is not many published evidence. However, our results showing increased transcripts for most of adenylyl cyclases (ADCY), as well as subunits of PRKA are in line with other authors who showed that adenosine and catecholamine analogs activate sperm motility by mechanisms that require atypical sperm ADCY and PRKACA [63] and that cAMP pathways are compartmentalized in sperm, with ADCY1-9 in the head and ADCY10 and PRKA in the flagellum [64]. Furthermore, PRKAR2A reduction in asthenozoospermic will likely decrease sperm quality [65], while Prkar $2 b$ is a potential heat sensitive target in germ cells [66]. Everything mentioned above is very important because CatSper channels are regulated by PRKA [67]. Additionally, our recent publication showed that ex vivo manipulation of stress signaling in spermatozoa changed transcriptional profiles of $84 \%$ mitochondrial dynamics / functionality markers and that most of these effects are mediated through $\alpha 1$-and/or- $\beta$-adrenergic receptors [14], which are very well known activators of ADCY-cAMP-PRKA-signaling [15]. In relation to MAPK signaling, our results are showing increased transcription of $80 \%$ of MAPKs, and 
they could be compared with findings that testicular hyperthermia induces both MAPK1/3 and MAPK14 [68] and that MEK1/2 and ERK2 regulate actin polymerization associated with spermatozoa capacitation [69].

Why is all of the aforementioned important? It has been shown that the stressful life, i.e., the alpha males ("life at the top") exhibited much higher stress hormone levels than second-ranking (beta) males [70]. Furthermore, spermatozoa functionality and male fertility are important not only as the fundamental markers of reproductive health, but also as the fundamental biomarker of overall health. Accordingly, urgent reactions are essential [2,3]. Why do we believe that our results provide a completely new view on testing of spermatozoa functionality and (sub/in)fertility? To prove that these results have direct and strong translational significance, we started analysis on human subjects. Preliminary results (Starovlah/Tomanic et al., unpublished results) showed correlation between different transcriptional profiles of mitochondrial dynamics markers and different types of spermiograms. Moreover, progesterone (acrosome-reaction-inducer) changed the transcriptional profile of some mitochondrial dynamics markers, suggesting direct relation with in vivo events required for fertilization. Accordingly, all presented molecular markers can be used as "mitochondrial-sperm-signature" to test spermatozoa functionality and (sub/in)fertility. These results are giving a new understanding of the correlation between stress and other life-style-environmental-one-health-factors, and male (in/sub)fertility. We believe that our work will be of significant interest to both basic research and clinical practice. This is because the preliminary results on a small number of human samples (12) showed dramatic changes in transcriptional profiles of mitochondrial dynamics markers between spermatozoa of teratozoospermic, asthenoteratozoospermic, and oligoasthenoteratozoospermic patients and normozoospermic patients. Moreover, according to the questionnaire completed by 89 patients, $91 \%$ reported some degree of stress: $44 \%$-low degree of stress, $36 \%$-frequent stressful situations, $11 \%$-high degree of stress (Starovlah/Tomanic et al. unpublished results).

\section{Materials and Methods}

All experiments were carried out in the Laboratory for Reproductive Endocrinology and Signaling and Laboratory for Chronobiology and Aging (wwwold.dbe.pmf.uns.ac. rs/en/nauka-eng/lares, accessed on 5 April 2021). The methods used in this study were carried out in accordance with the relevant guidelines and regulations. These methods were previously reported by our group (for all references please see $[13,14,46]$ ) and are outlined briefly here, but more details are available in Supplementary Materials.

\subsection{Statement of Institutional Review Board}

The manuscript is approved by the Committee of the Faculty of Sciences, University of Novi Sad.

\subsection{Statement That the Authors Complied with ARRIVE Guidelines and Institutional Animal Care and Use Committee Guidelines}

The authors complied with ARRIVE guidelines and all experiments were in adherence to the ARRIVE guidelines. Besides, all experimental protocols were approved (statement no. 01-201/3) by the local Ethical Committee on Animal Care and Use of the University of Novi Sad operating under the rules of National Council for Animal Welfare and the National Law for Animal Welfare (copyright March 2009), following the NRC publication Guide for the Care and Use of Laboratory Animals and NIH Guide for the Care and Use of Laboratory Animals.

\subsection{Animals and Experimental Model of Stress}

Three-months-old male Wistar rats were used for the experiments. Model of psychophysical stress by immobilization (IMO) was performed in the morning by the method previously described $[13,14,46]$. Briefly, animals were divided into the following groups: control—unstressed rats; $1 \times 3 \mathrm{hIMO}$-rats subjected to IMO once, for $3 \mathrm{~h} ; 10 \times 3 \mathrm{hIMO}$-rats 
subjected to repeat IMO of $3 \mathrm{~h}$ for 10 consecutive days. At the end of IMO period, animals were quickly decapitated without anesthesia. Serum samples were collected and assayed for androgens (testosterone + dihydrotestosterone; T + DHT), adrenaline, and corticosterone (CORT) levels. The experiment was repeated three times.

\subsection{Serum Hormones Measurement}

Measurement of hormone levels in serum was duplicated. The level of androgens was referred to as T + DHT since the anti-testosterone serum №250 showed $100 \%$ crossreactivity with DHT (sensitivity: 6 pg per tube; intra-assay coefficient of variation 5-8\%). Adrenaline levels were measured using the adrenaline research ELISA Kit (www.ldn.de, accessed on 5 April 2021) with the standard range of $0.45-45 \mathrm{ng} / \mathrm{mL}$ and detection limit of $3.9 \mathrm{pg} / \mathrm{mL}$. Corticosterone (CORT) levels were measured by the corticosterone EIA Kit (www.caymanchem.com, accessed on 5 April 2021) with $30 \mathrm{pg} / \mathrm{mL}$ as the lowest standard significantly different from blank.

\subsection{Isolation of Spermatozoa and Assessment of Their Functionality (Capacitation and Acrosome Reaction)}

Spermatozoa were isolated from caudal epididymides following the WHO laboratory manual (www.who.int/reproductivehealth/publications/infertility/9789241547789/en/, accessed on 5 April 2021) with modifications for rat spermatozoa isolation (for reference please see [14]). Caudal epididymides were quickly removed, placed in a Petri dish containing the medium for isolation and preservation of spermatozoa, finely punctuated with a needle, and incubated at $37^{\circ} \mathrm{C}$ for $10 \mathrm{~min}$. Released spermatozoa were collected, centrifuged for $5 \mathrm{~min}$ at $700 \times g$ and resuspended in the appropriate medium. Concentrations of isolated spermatozoa were calculated using a Makler counting chamber. To determine the functionality of the spermatozoa, approximately $1.5 \times 10^{5}$ spermatozoa in Whitten's Media were mixed with WH+ media (Whitten's Media supplemented with the $10 \mathrm{mg} / \mathrm{mL}$ BSA and $20 \mathrm{mM}$ of $\mathrm{NaHCO}_{3}$ ) with a drop of mineral oil, for $1 \mathrm{~h}$ at $37^{\circ} \mathrm{C}$. Capacitated spermatozoa were incubated without or with $15 \mu \mathrm{M}$ progesterone (PROG) for the activation of the acrosome reaction, for $30 \mathrm{~min}$ at $37^{\circ} \mathrm{C}$. After the incubation, spermatozoa suspension was fixed for $20 \mathrm{~min}$ and centrifuged for $1 \mathrm{~min}$ at $12,000 \times \mathrm{g}$. Spermatozoa in pellet were washed with $100 \mathrm{mM}$ ammonium acetate. The smears of fixed spermatozoa were air-dried and stained by covering the slides with staining solution, containing $0.04 \%$ Coomassie Blue-G250, for $5 \mathrm{~min}$ at room temperature, rinsed with distilled water and allowed to air-dry. The stained smears were analyzed using the microscope Leica DMLB $100 \mathrm{~T}$ with $1000 \times$ magnification. Ten to fifteen photos per slide were taken by Leica MC190 camera and LAS Version 4.8.0 software and up to 100 spermatozoa per slide counted to determine the acrosome status. Blue staining in the acrosome region of the head indicated intact acrosome, whereas spermatozoa without blue staining in the acrosome region were considered acrosome-reacted. Data are presented as the percentage of acrosome-reacted spermatozoa \pm SEM.

\subsection{Measurement of ATP Level}

The ATP level was determined using ATP Bioluminescence CLS II kit following the manufacturer's instructions (www.sigmaaldrich.com, accessed on 5 April 2021) Spermatozoa $\left(1 \times 10^{6}\right)$ were lysed in distilled $\mathrm{H}_{2} \mathrm{O}$ and mixed with Tris-EDTA in ratio of 1:9 $(v / v)$. Lysed spermatozoa in Tris-EDTA were incubated in water bath $\left(100{ }^{\circ} \mathrm{C} / 3 \mathrm{~min}\right)$, centrifuged for $1 \mathrm{~min}$ at $900 \times \mathrm{g}$. Supernatant was used for the measurement of ATP while the pellet was further used for measurement of protein concentration using Bradford protein assay. Sample and standard were mixed with Luciferase reagent in ratio of 1:1 $(v / v)$, and luminescence was measured by the Biosystems/luminometer (Fluoroscan, Ascent, FL, ThermoLabsystems, Helsinki, Finland), as described previously by our group (for references please see [71]). 


\subsection{RNA Isolation and cDNA Synthesis}

Isolation of total RNA was done using GenElute ${ }^{\mathrm{TM}}$ Mammalian Total RNA Miniprep Kit (www.sigmaaldrich.com, accessed on 5 April 2021), following the DNase I (RNase-free) treatment (www.neb.com, accessed on 5 April 2021). cDNA was synthesized using the High Capacity Kit (www.thermofisher.com, accessed on 5 April 2021). RNA quality and DNA integrity were checked using control primers for Gapdh.

\subsection{Relative Quantification of Gene Expression}

Relative quantification of gene expression was done by real-time PCR (RQ-PCR) using SYBR ${ }^{\circledR}$ Green-based chemistry (www.thermofisher.com, accessed on 5 April 2021) in the presence of cDNA and specific primers (Supplementary Tables S1-S7). The transcription of Gapdh was used to correct the variations in cDNA content between samples. Relative quantification of each gene was performed in duplicate, three times for each sample of three independent experiments.

\subsection{Statistical Analysis}

Results of the experiments represent group means \pm SEM values of the individual variation from three independent experiments (3 to 6 rats per group). Results from each experiment were analyzed by Mann-Whitney's unpaired non-parametric two-tailed test (for two-point data experiments), or by one-way ANOVA for group comparison, followed by Student-Newman-Keuls multiple range test. All the statistical analysis was done using GraphPad Prism 5 Software (GraphPad Software 287 Inc., La Jolla, CA, USA). In all cases, $p$-value $<0.05$ was considered to be statistically significant.

\section{Conclusions}

Psychophysical stress disturbs signaling pathways and molecules responsible for mitochondrial dynamics and functionality in spermatozoa with consequences for their functionality. Repeated stress changes 18-out-of-22 mitochondrial dynamics and functionality markers as well as 16-out-of-22 signaling molecules regulating mitochondrial dynamics/functionality in spermatozoa leading to reduced spermatozoa number/functionality important for male (in/sub)fertility. Stress-triggered changes of transcriptional profile of mitochondrial dynamics and functionality markers as well as signaling molecules regulating both mitochondrial dynamics and spermatozoa number and functionality represent adaptive mechanisms to keep spermatozoa functionality since ATP level is low. They do not only correlate with, but are also essential for spermatozoa functionality and (in/sub)fertility, considering that all events depend on the same regulators.

Supplementary Materials: The following are available online at https:/ /www.mdpi.com/article/10 $.3390 / \mathrm{ijms} 22115693 / \mathrm{s} 1$.

Author Contributions: I.M.S.-acquisition of the data; analysis and interpretation of the data; drafting the manuscript; revising manuscript critically for important intellectual content; final approval of the version to be submitted; S.M.R.P.-acquisition of the data; analysis and interpretation of the data; revising manuscript critically for important intellectual content; final approval of the version to be submitted; T.S.K.-acquisition of the data; analysis and interpretation of the data; revising manuscript critically for important intellectual content; final approval of the version to be submitted; S.A.A.- the conception and design of the research; acquisition of the data; analysis and interpretation of the data; drafting the manuscript; revising manuscript critically for important intellectual content; final approval of the version to be submitted. All authors agree to be accountable for all aspects of the work in ensuring that questions related to the accuracy or integrity of any part of the work are appropriately investigated and resolved; qualify for authorship, and all those who qualify for authorship are listed. All authors have read and agreed to the published version of the manuscript. 
Funding: This research was supported by the Serbian Ministry of Education, Science and Technological Development (CIV-CeRES grant, S.Andric; grant number 173057, T. Kostic) the Autonomous Province of Vojvodina (grant number 2130, S. Andric).

Institutional Review Board Statement: The manuscript is approved by the Committee of the Faculty of Sciences, University of Novi Sad. The authors complied with ARRIVE guidelines and all experiments were in adherence to the ARRIVE guidelines. Besides, all experimental protocols were approved (statement no. 01-201/3) by the local Ethical Committee on Animal Care and Use of the University of Novi Sad operating under the rules of National Council for Animal Welfare and the National Law for Animal Welfare (copyright March 2009), following the NRC publication Guide for the Care and Use of Laboratory Animals and NIH Guide for the Care and Use of Laboratory Animals.

Informed Consent Statement: Not applicable.

Data Availability Statement: All relevant data and samples are available from the corresponding author on request. Further information and requests for resources and reagents should be directed to and will be fulfilled by the Lead Contact, Silvana Andric (silvana.andric@dbe.uns.ac.rs, accessed on 12 April 2021).

Acknowledgments: This work was supported by grants from the Serbian Ministry of Education, Science and Technological Development (CeRES grant, S.Andric; grant number 173057, T. Kostic) and Autonomous Province of Vojvodina (grant number 2130, S. Andric). We are very grateful to G. Niswender for antibodies for RIA analysis. We are very grateful to Strahinja Keselj for help with English language editing.

Conflicts of Interest: The authors declare no conflict of interest.

\section{References}

1. Barbagallo, F.; La Vignera, S.; Cannarella, R.; Aversa, A.; Calogero, A.E.; Condorelli, R.A. Evaluation of Sperm Mitochondrial Function: A Key Organelle for Sperm Motility. J. Clin. Med. 2020, 9, 363. [CrossRef]

2. Choy, J.T.; Eisenberg, M.L. Male Infertility as a Window to Health. Fertil. Steril. 2018, 110, 810-814. [CrossRef]

3. Bräuner, E.V.; Nordkap, L.; Priskorn, L.; Hansen, Å.M.; Bang, A.K.; Holmboe, S.A.; Schmidt, L.; Jensen, T.K.; Jørgensen, N. Psychological Stress, Stressful Life Events, Male Factor Infertility, and Testicular Function: A Cross-Sectional Study. Fertil. Steril. 2020, 113, 865-875. [CrossRef] [PubMed]

4. Nordkap, L.; Jensen, T.K.; Hansen, Å.M.; Lassen, T.H.; Bang, A.K.; Joensen, U.N.; Jensen, M.B.; Skakkebæk, N.E.; Jørgensen, N. Psychological Stress and Testicular Function: A Cross-Sectional Study of 1215 Danish Men. Fertil. Steril. 2016, 105, 174-187.e2. [CrossRef] [PubMed]

5. Yazawa, H.; Sasagawa, I.; Ishigooka, M.; Nakada, T. Effect of Immobilization Stress on Testicular Germ Cell Apoptosis in Rats. Hum. Reprod. 1999, 14. [CrossRef] [PubMed]

6. Nirupama, M.; Devaki, M.; Nirupama, R.; Yajurvedi, H.N. Chronic Intermittent Stress-Induced Alterations in the Spermatogenesis and Antioxidant Status of the Testis Are Irreversible in Albino Rat. J. Physiol. Biochem. 2013, 69, 59-68. [CrossRef]

7. Selye, H. A Syndrome Produced by Diverse Nocuous Agents. Nature 1936, 138, 32. [CrossRef]

8. Chrousos, G.P. Stress and Disorders of the Stress System. Nat. Rev. Endocrinol. 2009, 5, 374-381. [CrossRef] [PubMed]

9. Manoli, I.; Alesci, S.; Blackman, M.R.; Su, Y.A.; Rennert, O.M.; Chrousos, G.P. Mitochondria as Key Components of the Stress Response. Trends Endocrinol. Metab. 2007, 18, 190-198. [CrossRef]

10. Pitman, R.K.; Rasmusson, A.M.; Koenen, K.C.; Shin, L.M.; Orr, S.P.; Gilbertson, M.W.; Milad, M.R.; Liberzon, I. Biological Studies of Post-Traumatic Stress Disorder. Nat. Rev. Neurosci. 2012, 13, 769-787. [CrossRef]

11. Sapolsky, R.M. The Influence of Social Hierarchy on Primate Health. Science 2005, 308, 648-652. [CrossRef]

12. Selye, H. Stress and Disease. Science 1955, 122, 625-631. [CrossRef] [PubMed]

13. Gak, I.A.; Radovic, S.M.; Dukic, A.R.; Janjic, M.M.; Stojkov-Mimic, N.J.; Kostic, T.S.; Andric, S.A. Stress Triggers Mitochondrial Biogenesis to Preserve Steroidogenesis in Leydig Cells. Biochim. Biophys. Acta BBA Mol. Cell Res. 2015, 1853, 2217-2227. [CrossRef]

14. Starovlah, I.M.; Radovic Pletikosic, S.M.; Kostic, T.S.; Andric, S.A. Reduced Spermatozoa Functionality during Stress Is the Consequence of Adrenergic-Mediated Disturbance of Mitochondrial Dynamics Markers. Sci. Rep. 2020, 10, 16813. [CrossRef] [PubMed]

15. Hara, M.R.; Kovacs, J.J.; Whalen, E.J.; Rajagopal, S.; Strachan, R.T.; Grant, W.; Towers, A.J.; Williams, B.; Lam, C.M.; Xiao, K.; et al. A Stress Response Pathway Regulates DNA Damage through B2-Adrenoreceptors and $\beta$-Arrestin-1. Nature 2011, 477, 349-353. [CrossRef] [PubMed]

16. Mhaouty-Kodja, S.; Lozach, A.; Habert, R.; Tanneux, M.; Guigon, C.; Brailly-Tabard, S.; Maltier, J.-P.; Legrand-Maltier, C. Fertility and Spermatogenesis Are Altered in 1b-Adrenergic Receptor Knockout Male Mice. J. Endocrinol. 2007, 195, 281-292. [CrossRef]

17. Gallon, F.; Marchetti, C.; Jouy, N.; Marchetti, P. The Functionality of Mitochondria Differentiates Human Spermatozoa with High and Low Fertilizing Capability. Fertil. Steril. 2006, 86, 1526-1530. [CrossRef] 
18. Kao, S.-H.; Chao, H.-T.; Liu, H.-W.; Liao, T.-L.; Wei, Y.-H. Sperm Mitochondrial DNA Depletion in Men with Asthenospermia. Fertil. Steril. 2004, 82, 66-73. [CrossRef]

19. Song, G.J.; Lewis, V. Mitochondrial DNA Integrity and Copy Number in Sperm from Infertile Men. Fertil. Steril. 2008, 90, 2238-2244. [CrossRef]

20. Okuda, H.; Tsujimura, A.; Yamamoto, K.; Fukuhara, S.; Nakayama, J.; Kiuchi, H.; Takao, T.; Miyagawa, Y.; Nonomura, N.; Okuyama, A. Morphologic and Mitochondrial Characterization of Human Spermatogenic Cells Dispersed in Wet Preparation for Testicular Sperm Extraction: Establishment of a Microscopic Diagram of Developing Human Spermatogenic Cells. Fertil. Steril. 2011, 95, 2665-2668. [CrossRef]

21. Pelliccione, F.; Micillo, A.; Cordeschi, G.; D'Angeli, A.; Necozione, S.; Gandini, L.; Lenzi, A.; Francavilla, F.; Francavilla, S. Altered Ultrastructure of Mitochondrial Membranes Is Strongly Associated with Unexplained Asthenozoospermia. Fertil. Steril. 2011, 95, 641-646. [CrossRef] [PubMed]

22. Carra, E.; Sangiorgi, D.; Gattuccio, F.; Rinaldi, A.M. Male Infertility and Mitochondrial DNA. Biochem. Biophys. Res. Commun. 2004, 322, 333-339. [CrossRef] [PubMed]

23. Gholinezhad, M.; Yousefnia-pasha, Y.; Colagar, A.H.; Mohammadoo-Khorasani, M.; Bidmeshkipour, A. Comparison of LargeScale Deletions of the Sperm Mitochondrial DNA in Normozoospermic and Asthenoteratozoospermic Men. J. Cell. Biochem. 2019, 120, 1958-1968. [CrossRef] [PubMed]

24. Lu, X.; Zhang, Y.; Bai, H.; Liu, J.; Li, J.; Wu, B. Mitochondria-Targeted Antioxidant MitoTEMPO Improves the Post-Thaw Sperm Quality. Cryobiology 2018, 80, 26-29. [CrossRef]

25. Paoli, D.; Gallo, M.; Rizzo, F.; Baldi, E.; Francavilla, S.; Lenzi, A.; Lombardo, F.; Gandini, L. Mitochondrial Membrane Potential Profile and Its Correlation with Increasing Sperm Motility. Fertil. Steril. 2011, 95, 2315-2319. [CrossRef]

26. Zhang, G.; Yang, W.; Zou, P.; Jiang, F.; Zeng, Y.; Chen, Q.; Sun, L.; Yang, H.; Zhou, N.; Wang, X.; et al. Mitochondrial Functionality Modifies Human Sperm Acrosin Activity, Acrosome Reaction Capability and Chromatin Integrity. Hum. Reprod. 2019, 34, 3-11. [CrossRef]

27. Malić Vončina, S.; Golob, B.; Ihan, A.; Kopitar, A.N.; Kolbezen, M.; Zorn, B. Sperm DNA Fragmentation and Mitochondrial Membrane Potential Combined Are Better for Predicting Natural Conception than Standard Sperm Parameters. Fertil. Steril. 2016, 105, 637-644.e1. [CrossRef]

28. Amaral, A.; Ramalho-Santos, J.; St John, J.C. The Expression of Polymerase Gamma and Mitochondrial Transcription Factor A and the Regulation of Mitochondrial DNA Content in Mature Human Sperm. Hum. Reprod. 2007, 22, 1585-1596. [CrossRef]

29. Borges, E.; Zanetti, B.F.; Setti, A.S.; Braga, D.P.d.A.F.; Provenza, R.R.; Iaconelli, A. Sperm DNA Fragmentation Is Correlated with Poor Embryo Development, Lower Implantation Rate, and Higher Miscarriage Rate in Reproductive Cycles of Non-Male Factor Infertility. Fertil. Steril. 2019, 112, 483-490. [CrossRef]

30. Faja, F.; Carlini, T.; Coltrinari, G.; Finocchi, F.; Nespoli, M.; Pallotti, F.; Lenzi, A.; Lombardo, F.; Paoli, D. Human Sperm Motility: A Molecular Study of Mitochondrial DNA, Mitochondrial Transcription Factor A Gene and DNA Fragmentation. Mol. Biol. Rep. 2019, 46, 4113-4121. [CrossRef]

31. Aparicio, I.M.; Espino, J.; Bejarano, I.; Gallardo-Soler, A.; Campo, M.L.; Salido, G.M.; Pariente, J.A.; Peña, F.J.; Tapia, J.A. Autophagy-Related Proteins Are Functionally Active in Human Spermatozoa and May Be Involved in the Regulation of Cell Survival and Motility. Sci. Rep. 2016, 6, 33647. [CrossRef] [PubMed]

32. Wang, X.; Qian, H.; Huang, X.; Li, J.; Zhang, J.; Zhu, N.; Chen, H.; Zhu, C.; Wang, J.; Zhang, P.; et al. UCP2 Mitigates the Loss of Human Spermatozoa Motility by Promoting MROS Elimination. Cell. Physiol. Biochem. 2018, 50, 952-962. [CrossRef] [PubMed]

33. Fang, F.; Ni, K.; Shang, J.; Zhang, X.; Xiong, C.; Meng, T. Expression of Mitofusin 2 in Human Sperm and Its Relationship to Sperm Motility and Cryoprotective Potentials. Exp. Biol. Med. 2018, 243, 963-969. [CrossRef] [PubMed]

34. Silva, J.V.; Freitas, M.J.; Correia, B.R.; Korrodi-Gregório, L.; Patrício, A.; Pelech, S.; Fardilha, M. Profiling Signaling Proteins in Human Spermatozoa: Biomarker Identification for Sperm Quality Evaluation. Fertil. Steril. 2015, 104, 845-856.e8. [CrossRef] [PubMed]

35. Dominy, J.E.; Puigserver, P. Mitochondrial Biogenesis through Activation of Nuclear Signaling Proteins. Cold Spring Harb. Perspect. Biol. 2013, 5, a015008. [CrossRef] [PubMed]

36. Markaki, M.; Tavernarakis, N. Mitochondrial Turnover and Homeostasis in Ageing and Neurodegeneration. FEBS Lett. 2020, 594, 2370-2379. [CrossRef]

37. Scarpulla, R.C. Transcriptional Paradigms in Mammalian Mitochondrial Biogenesis and Function. Physiol. Rev. 2008, 88, 611-638. [CrossRef]

38. Scarpulla, R.C.; Vega, R.B.; Kelly, D.P. Transcriptional Integration of Mitochondrial Biogenesis. Trends Endocrinol. Metab. 2012, 23, 459-466. [CrossRef]

39. Finkel, T. A Clean Energy Programme. Nature 2006, 444, 151-152. [CrossRef]

40. Pyakurel, A.; Savoia, C.; Hess, D.; Scorrano, L. Extracellular Regulated Kinase Phosphorylates Mitofusin 1 to Control Mitochondrial Morphology and Apoptosis. Mol. Cell 2015, 58, 244-254. [CrossRef]

41. Rodgers, J.T.; Lerin, C.; Haas, W.; Gygi, S.P.; Spiegelman, B.M.; Puigserver, P. Nutrient Control of Glucose Homeostasis through a Complex of PGC-1alpha and SIRT1. Nature 2005, 434, 113-118. [CrossRef] [PubMed] 
42. García-Bueno, B.; Madrigal, J.L.M.; Pérez-Nievas, B.G.; Leza, J.C. Stress Mediators Regulate Brain Prostaglandin Synthesis and Peroxisome Proliferator-Activated Receptor-Gamma Activation after Stress in Rats. Endocrinology 2008, 149, 1969-1978. [CrossRef] [PubMed]

43. Weber, K.; Brück, P.; Mikes, Z.; Küpper, J.-H.; Klingenspor, M.; Wiesner, R.J. Glucocorticoid Hormone Stimulates Mitochondrial Biogenesis Specifically in Skeletal Muscle. Endocrinology 2002, 143, 177-184. [CrossRef]

44. Krauss, S.; Zhang, C.-Y.; Lowell, B.B. The Mitochondrial Uncoupling-Protein Homologues. Nat. Rev. Mol. Cell Biol. 2005, 6, 248-261. [CrossRef]

45. Echave, P.; Machado-da-Silva, G.; Arkell, R.S.; Duchen, M.R.; Jacobson, J.; Mitter, R.; Lloyd, A.C. Extracellular Growth Factors and Mitogens Cooperate to Drive Mitochondrial Biogenesis. J. Cell Sci. 2009, 122, 4516-4525. [CrossRef] [PubMed]

46. Boguenet, M.; Bouet, P.-E.; Spiers, A.; Reynier, P.; May-Panloup, P. Mitochondria: Their role in spermatozoa and in male infertility. Hum. Reprod. Update 2021. [CrossRef]

47. Starovlah, I.M.; Sava, R.M.; Marinovic, M.A.; Kostic, T.S.; Andric, S.A. Psychophysical Stress Disturbs Expression of Mitochondrial Biogenesis Markers in Hypothalamus and Adenohypophysis. Biol. Serbica 2017, 39, 43-51.

48. Hou, G.; Xiong, W.; Wang, M.; Chen, X.; Yuan, T. Chronic Stress Influences Sexual Motivation and Causes Damage to Testicular Cells in Male Rats. J. Sex. Med. 2014, 11, 653-663. [CrossRef]

49. Mehfooz, A.; Wei, Q.; Zheng, K.; Fadlalla, M.B.; Maltasic, G.; Shi, F. Protective Roles of Rutin against Restraint Stress on Spermatogenesis in Testes of Adult Mice. Tissue Cell 2018, 50, 133-143. [CrossRef]

50. Demirci, T.; Sahin, E. The Effect of Chronic Stress and Obesity on Sperm Quality and Testis Histology in Male Rats: A Morphometric and Immunohistochemical Study. Histol. Histopathol. 2019, 34, 287-302.

51. Zou, P.; Wang, X.; Yang, W.; Liu, C.; Chen, Q.; Yang, H.; Zhou, N.; Zeng, Y.; Chen, H.; Zhang, G.; et al. Mechanisms of Stress-Induced Spermatogenesis Impairment in Male Rats Following Unpredictable Chronic Mild Stress (UCMS). Int. J. Mol. Sci. 2019, 20, 4470. [CrossRef]

52. De Souza, M.J.; Arce, J.C.; Pescatello, L.S.; Scherzer, H.S.; Luciano, A.A. Gonadal Hormones and Semen Quality in Male Runners. A Volume Threshold Effect of Endurance Training. Int. J. Sports Med. 1994, 15, 383-391. [CrossRef] [PubMed]

53. Fenster, L.; Katz, D.F.; Wyrobek, A.J.; Pieper, C.; Rempel, D.M.; Oman, D.; Swan, S.H. Effects of Psychological Stress on Human Semen Quality. J. Androl. 1997, 18, 194-202. [PubMed]

54. Elezaj, S.; Gashi, Z.; Zeqiraj, A.; Grabanica, D.; Shllaku, A.; Gruda, B.; Musaj, V. Treatment of Infertility in Men with Post-Traumatic Stress Disorder (PTSD) with the Method of Intrauterine Insemination. Med. Arch. 2015, 69, 327-330. [CrossRef] [PubMed]

55. Chen, X.; Lin, Q.; Wen, J.; Lin, W.; Liang, J.; Huang, H.; Li, L.; Huang, J.; Chen, F.; Liu, D.; et al. Whole Genome Bisulfite Sequencing of Human Spermatozoa Reveals Differentially Methylated Patterns from Type 2 Diabetic Patients. J. Diabetes Investig. 2020, 11, 856-864. [CrossRef]

56. Gawish, R.A.; Fahmy, H.A.; Abd El Fattah, A.I.; Nada, A.S. The Potential Effect of Methylseleninic Acid (MSA) against $\gamma-$ Irradiation Induced Testicular Damage in Rats: Impact on JAK/STAT Pathway. Arch. Biochem. Biophys. 2020, 679, 108205. [CrossRef]

57. Larsson, N.G.; Garman, J.D.; Oldfors, A.; Barsh, G.S.; Clayton, D.A. A Single Mouse Gene Encodes the Mitochondrial Transcription Factor A and a Testis-Specific Nuclear HMG-Box Protein. Nat. Genet. 1996, 13, 296-302. [CrossRef] [PubMed]

58. Varuzhanyan, G.; Rojansky, R.; Sweredoski, M.J.; Graham, R.L.; Hess, S.; Ladinsky, M.S.; Chan, D.C. Mitochondrial Fusion Is Required for Spermatogonial Differentiation and Meiosis. eLife 2019, 8, e51601. [CrossRef] [PubMed]

59. Binder, N.K.; Sheedy, J.R.; Hannan, N.J.; Gardner, D.K. Male Obesity Is Associated with Changed Spermatozoa Cox4i1 MRNA Level and Altered Seminal Vesicle Fluid Composition in a Mouse Model. Mol. Hum. Reprod. 2015, 21, 424-434. [CrossRef] [PubMed]

60. An, J.; Zhang, X.; Qin, J.; Wan, Y.; Hu, Y.; Liu, T.; Li, J.; Dong, W.; Du, E.; Pan, C.; et al. The Histone Methyltransferase ESET Is Required for the Survival of Spermatogonial Stem/Progenitor Cells in Mice. Cell Death Dis. 2014, 5, e1196. [CrossRef]

61. Zhang, W.-D.; Zhang, Z.; Jia, L.-T.; Zhang, L.-L.; Fu, T.; Li, Y.-S.; Wang, P.; Sun, L.; Shi, Y.; Zhang, H.-Z. Oxygen Free Radicals and Mitochondrial Signaling in Oligospermia and Asthenospermia. Mol. Med. Rep. 2014, 10, 1875-1880. [CrossRef]

62. Finkelstein, M.; Etkovitz, N.; Breitbart, H. Ca2+ Signaling in Mammalian Spermatozoa. Mol. Cell. Endocrinol. 2020, 516, 110953. [CrossRef] [PubMed]

63. Schuh, S.M.; Carlson, A.E.; McKnight, G.S.; Conti, M.; Hille, B.; Babcock, D.F. Signaling Pathways for Modulation of Mouse Sperm Motility by Adenosine and Catecholamine Agonists. Biol. Reprod. 2006, 74, 492-500. [CrossRef]

64. Wertheimer, E.; Krapf, D.; de la Vega-Beltran, J.L.; Sánchez-Cárdenas, C.; Navarrete, F.; Haddad, D.; Escoffier, J.; Salicioni, A.M.; Levin, L.R.; Buck, J.; et al. Compartmentalization of Distinct CAMP Signaling Pathways in Mammalian Sperm. J. Biol. Chem. 2013, 288, 35307-35320. [CrossRef] [PubMed]

65. Capkova, J.; Kubatova, A.; Ded, L.; Tepla, O.; Peknicova, J. Evaluation of the Expression of Sperm Proteins in Normozoospermic and Asthenozoospermic Men Using Monoclonal Antibodies. Asian J. Androl. 2016, 18, 108-113. [PubMed]

66. Yadav, S.K.; Pandey, A.; Kumar, L.; Devi, A.; Kushwaha, B.; Vishvkarma, R.; Maikhuri, J.P.; Rajender, S.; Gupta, G. The Thermo-Sensitive Gene Expression Signatures of Spermatogenesis. Reprod. Biol. Endocrinol. RBE 2018, 16, 56. [CrossRef] [PubMed]

67. Orta, G.; de la Vega-Beltran, J.L.; Martín-Hidalgo, D.; Santi, C.M.; Visconti, P.E.; Darszon, A. CatSper Channels Are Regulated by Protein Kinase A. J. Biol. Chem. 2018, 293, 16830-16841. [CrossRef] 
68. Jia, Y.; Castellanos, J.; Wang, C.; Sinha-Hikim, I.; Lue, Y.; Swerdloff, R.S.; Sinha-Hikim, A.P. Mitogen-Activated Protein Kinase Signaling in Male Germ Cell Apoptosis in the Rat1. Biol. Reprod. 2009, 80, 771-780. [CrossRef]

69. Salgado-Lucio, M.L.; Ramírez-Ramírez, D.; Jorge-Cruz, C.Y.; Roa-Espitia, A.L.; Hernández-González, E.O. FAK Regulates Actin Polymerization during Sperm Capacitation via the ERK2/GEF-H1/RhoA Signaling Pathway. J. Cell Sci. 2020, 133 , jcs239186. [CrossRef] [PubMed]

70. Gesquiere, L.R.; Learn, N.H.; Simao, M.C.M.; Onyango, P.O.; Alberts, S.C.; Altmann, J. Life at the Top: Rank and Stress in Wild Male Baboons. Science 2011, 333, 357-360. [CrossRef]

71. Medar, M.L.J.; Marinkovic, D.Z.; Kojic, Z.; Becin, A.P.; Starovlah, I.M.; Kravic-Stevovic, T.; Andric, S.A.; Kostic, T.S. Dependence of Leydig Cell's Mitochondrial Physiology on Luteinizing Hormone Signaling. Life 2021, 11, 19. [CrossRef] [PubMed] 